\title{
MORE THAN WORDS: TEXT MATTERS IN LANGUAGE LEARNING
}

\author{
Meng Huat, Chau \\ University of Malaya
}

\begin{abstract}
In this paper, I discuss one possible line of approach towards enabling learners to develop their appreciation of the linguistic resources that contribute to the creation of discourse as well as their control of language use at the discourse level. I argue that texts, spoken or written, are critical language learning resources and that they need to be selectively employed and connected with well-developed tasks to provide supporting frameworks within which opportunities for language learning can be maximized. The interplay between text, task and reflection is emphasized and student feedback on the proposed approach is considered. The discussion in this paper complements most other discussion on discourse analysis which is concerned solely with spoken interaction as reflected in such approaches as exchange structure and conversation analysis (e.g., McCarthy \& Walsh, 2003; see also Cook, 2011).
\end{abstract}

$\begin{array}{ll}\text { KEYWORDS: } & \text { TEXTS AS LANGUAGE LEARNING RESOURCES, PEDAGOGIC } \\ & \text { CORPUS, DISCOURSE PATTERN, REFLECTION, LANGUAGE } \\ & \text { LEARNING, DISCOURSE APPROACH TO LANGUAGE TEACHING }\end{array}$

\section{Introduction}

Some 10 years ago, Hyland (2008) talked of genre being seen by many teachers as more of a research tool than a teaching one. This, as Hyland points out, is a general misconception. The same may be said of discourse analysis as a whole (cf. Ferris, 2011). It is true that discourse analysis is often perceived as an academic study on university linguistics and English language programmes, but when taken as a pedagogical approach, analysis of discourse data essentially engages students in meaningful interpretation and production of texts, written or spoken (cf. Woods, 2007). A discourse approach to language teaching then suggests working with texts, enabling learners to see text as a site for social interaction and interpersonal meaning-making (Halliday, 1978), and scaffolding their effective use and production of texts.

This paper offers one possible line of approach towards meaningfully engaging learners in the construction and interpretation of texts, and towards enabling them to develop a deep appreciation and control of language use at the discourse level. I argue that texts are critical language learning resources and that they need to be selectively employed and connected with well-developed tasks to provide supporting frameworks within which opportunities for language learning can be promoted. The first part of the paper examines and discusses a pedagogic text to exemplify some potential problems (as well as learning opportunities) English texts in general create for the classroom learner. The second part, drawing insights from the earlier discussion, first briefly considers some issues of how to go about selecting and assembling texts, and then presents a framework concerning the use of carefully selected texts and related tasks that is aimed at maximizing language learning opportunities. 


\section{MORE THAN WORDS: TEXT MATTERS IN LANGUAGE LEARNING}

Student feedback is considered, with further cautionary notes on viewing learner language and on introducing change in educational practices.

\section{Text and discourse patterns}

In this section, I have chosen to focus on the pedagogic text for our discussion. This choice is motivated by the observation that pedagogic texts are a main source of language which teachers, especially those working in the socio-cultural context of English language teaching (ELT) in countries such as Malaysia, frequently provide as classroom input or 'experience' for learners. The text in focus is taken from a book published locally by Oxford Fajar (2007). It was written and published as a model essay for secondary school students of English. It is illustrative of typical classroom texts that these learners regularly encounter (the text has been shortened for reasons of space):

A very good morning to the Principal, teachers and friends. Today is World Environment Day and it is a day when we must thank God for all the wonderful gifts we enjoy from nature and hope that we do not lose them through our careless actions.

We must do our part in safeguarding the environment. The young people of today must remember that we are the guardians of this world just as our forefathers were before us. It is all too easy to enjoy the gifts of nature and forget that it is our role to look after them for future generations. This is a duty we cannot afford to neglect.

Let us not do things against nature. Let us not cut down trees carelessly. Let us not kill animals for their fur, meat and feathers indiscriminately. Let the rivers that flow through the forests abound with fish. Let them not be polluted. Do not use the rivers as our dumping grounds. Surely we must enjoy fresh air and appreciate the beautiful plants and trees around us? If greed and ignorance blind our eyes, then we stand to lose these gifts of nature forever.

For a start, love the plants and trees around us. Remember, they are homes to numerous birds, butterflies and insects. If we destroy these trees, we destroy the homes of these creatures and what will life be like without these colourful creatures? We need to hear the chirping of birds and the sound of crickets to know that man is one with nature. Indeed our lives will be empty without the wonderful joys of nature.

We are only doing ourselves a favour by looking after this planet. Remember, it is our planet, the only one we have. Thank you

This text exemplifies one popular rhetorical or discourse pattern of English texts: the general-specific pattern. The first paragraph provides a general statement on the importance of nature with its 'wonderful gifts'. It ends with an expression of hope that we will not lose the gifts 'through our careless actions', signalling to the reader to anticipate further, specific discussion on how to safeguard our environment to ensure that we continue to enjoy all the good things provided by Mother Nature. We find that the next three paragraphs provide specific discussion indeed which expands upon and adds details to the initial general ideas expressed in the first paragraph. The last paragraph concludes by stressing the importance of looking after Mother Nature, linking back to the general topic under discussion: the environment, its importance and ways to safeguard it.

The general-to-specific structure of this text can be diagrammatically represented as follows: 


\section{MORE THAN WORDS: TEXT MATTERS IN LANGUAGE LEARNING}

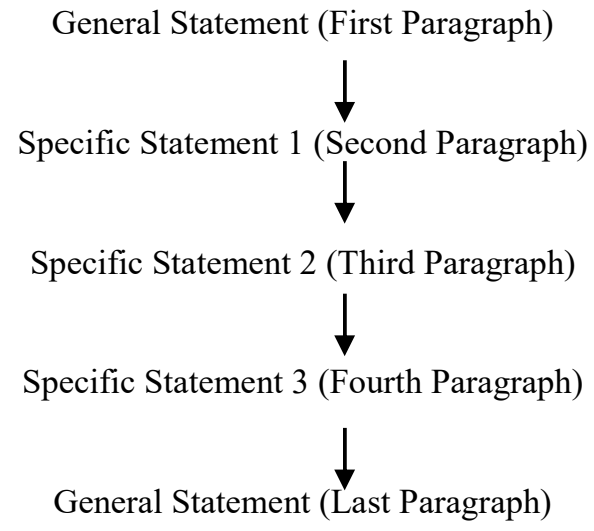

Alternatively, we can view the Environment text above as reflecting another very common discourse pattern in English: the problem-solution pattern. The first paragraph of the text highlights the importance of Mother Nature and suggests a potential problem - we may lose all the 'wonderful gifts' from nature if we show little care for the environment. The next three paragraphs note our role to safeguard the environment and discuss possible solutions to the problem. The conclusion in the last paragraph restates the importance of taking care of Mother Nature: We are only doing ourselves a favour by looking after this planet. Remember, it is our planet, the only one we have.

This Environment text is but one example of the many texts in English with the problem-solution pattern; it is not difficult to find texts of shorter length but which exhibit the same discourse pattern. Here is an example:

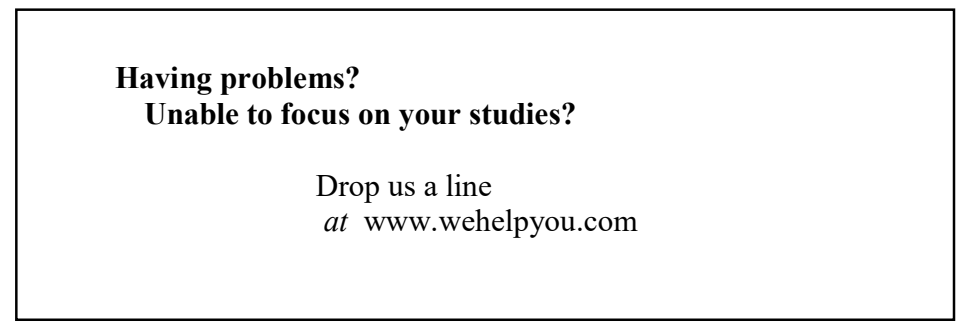

Figure 1: A text showing the problem-solution pattern

Figure 1 presents an example text familiar to those classroom teachers in Malaysia who are preparing their students for the public examination. The students are to first read and understand the short text and then answer a comprehension question based on the text. Again, we find that students are presented with a text of (and by implication, the task of interpreting) the problem-solution pattern: if one has problems staying focused (problem), one can visit and consult the website (solution) as suggested. Notice how the word problems as in having problems contributes to realizing the larger problemsolution discourse pattern. Discourse-organizing words of this kind have been suggested to both signal and reinforce the organization of text (McCarthy, 1991). 


\section{MORE THAN WORDS: TEXT MATTERS IN LANGUAGE LEARNING}

This problem-solution pattern is one of the most frequently recurring yet distinctive textual patterns that operate at the level of discourse in English. Other common discourse patterns in addition to the 'general-to-specific' pattern noted earlier include 'claim-counter-claim', 'gap in knowledge-filling', 'hypothetical-real' and 'question-answer'. It is important to recognize that certain patterns tend to occur more frequently in particular texts than others. For example, while the 'claim-counter-claim' pattern is common in the letters-to-the-editor pages of newspapers, the 'gap in knowledge-filling' structure is frequent in academic papers as well as detective stories (see Hoey, 1983, 2001; Winter, 1986 and McCarthy, 1991 for further discussion on patterning in text).

Our discussion thus far suggests that there exists a distinct preference for certain texts to be organized in certain discourse patterns. That is to say, these patterns seem to reflect 'culturally approved' preferences for certain texts to be organized in particular ways. This is perhaps not too surprising when one considers that texts, like most works of art and scientific experiments, are built on earlier creations (Gardner, 1993) and that the shape a text takes is a result of decades of accumulated work and practice by users of the language. Relevant to this is the classroom implication that a learner who is not aware of distinctive discourse patterns may have problems interpreting or producing 'culturally preferred' texts in the target language (cf. McCarthy, 1991). Although this clearly points to the need for pedagogic intervention, it is not always easy to see what constitutes relevant and appropriate pedagogic actions in the classroom.

It is possible to imagine that the teacher explicitly informs the students about the various textual patterns in English. In most cases, however, more student exploration and deeper processing of texts are needed before direct teaching can prove effective. We will return to pedagogical issues of this kind when we consider texts as language learning resources shortly.

\section{Text, lexis and grammar}

Concerns about discourse patterns are, of course, not the only problem our learners face when encountering target-language texts. Recognizing the existence of a complex but systematic interplay between text, lexis and grammar, and pressing the relevant lexical-grammatical resources (after Sinclair's (2004) notion of lexical grammar) into communicative use, prove equally, if not more, challenging to learners. It is crucial that learners are guided to develop an appreciation of seeing lexicalgrammatical selections as motivated choices in context which shape and are shaped by different texts that serve different social functions. Since discussion abounds on the role of lexis and grammar in discourse (e.g., McCarthy, 1991; Celce-Murcia \& Olshtain, 2000, 2014; Thornbury, 2005), this section will focus on one specific area of linguistic resources relatively less addressed in the literature but which has a direct role to play in the discourse process: topic-related vocabulary.

Let us begin by considering the following list of the 10 most frequent content words from a text (that we are all familiar with if we have been following the discussion) with their corresponding frequency count, and see what clues they provide that tell us what the text might be about:

$\begin{array}{ll}\text { nature } & 6 \\ \text { let } & 5 \\ \text { trees } & 4 \\ \text { gifts } & 3 \\ \text { enjoy } & 3 \\ \text { remember } & 3 \\ \text { birds } & 2 \\ \text { creatures } & 2\end{array}$




\title{
MORE THAN WORDS: TEXT MATTERS IN LANGUAGE LEARNING
}

\author{
destroy 2 \\ day 2
}

Looking at these 10 content words, one should have no problem recognizing that the text is about nature or the environment, as indicated by such words as nature $(\mathrm{n}=6)$, trees $(\mathrm{n}=4)$, birds $(\mathrm{n}=2)$ and creatures $(\mathrm{n}=2)$ on the list. Other words such as let $(\mathrm{n}=5)$ and remember $(\mathrm{n}=3)$, whose relative frequencies can be considered to be markedly high here, seem to urge caution or offer advice, suggesting something needs to be addressed in relation to the environment. As the reader might have guessed by now, these topic-related words are some top high frequency content words identified through a frequency analysis of the Environment text which we have examined earlier.

It is important to point out that it is not by chance that this topic-related vocabulary recurs frequently in the text. Topic-related words, as socially motivated linguistic choices, perform the functions of characterizing and distinguishing one text from another and convey the author's intended message. That is, they reveal the primary message of the author or the essence of the text.

How the essence of a text may be revealed through topic-related words, obvious though they may be to the teacher but not always necessarily so to the learner, is further exemplified in the following 'task' completed by my upper secondary school students in a class I had with them some years ago. The students were asked to identify and write down groups of content words (i.e., nouns, verbs, adjectives, adverbs) from a text on pollution which they had studied (this Pollution text is unfortunately not publishable for copyright reasons). The resulting collaborative work looks something like the one presented below:

Words connected with the problem:

(nouns) environment; pollution

(adjective) environmental

(adverb) environmentally

Words connected with the people involved:

(nouns) consumer(s); Department of the Environment; government; industries; parties; people; public; Road Transport Department; vehicle owners

(adjectives) average; ignorant

Words connected with causes of the problem:

(nouns) industrialization; modernization

chlorofluorocarbons; fumes; materials; waste

dumping; emission; use

(verb) contribute (to)

(adjectives) disposable; indestructible; indiscriminate; major; toxic; unchecked

Words connected with consequences of the problem:

(nouns) effects; price

(verb) destroy

(adjective) inevitable

Words connected with solutions to the problem:

(nouns) awareness; control; efforts; encouragement; laws; move; regulations; step

catalytic converters; (environmentally safe/environment-friendly/green)

products; lead-free petrol; waste-treatment systems 


\title{
MORE THAN WORDS: TEXT MATTERS IN LANGUAGE LEARNING
}

\author{
(verbs) comply (with); educate; enforced; ensure; equipped (with); informed; \\ installing; made aware; recycled; using \\ curb; cutting down; help; prevent; protect; reduc(e/ing); \\ (adjectives) attractive; biodegradable; commendable; effective; environment-friendly; \\ green; important; proper; public; reasonable; recycled; safe; stricter \\ (adverbs) \\ better; strictly
}

The content words cluster around such larger elements fundamental to the text as 'problem' and 'solution'. Note how they carry the message of the text: they capture the very essence of the text and at the same time characterize the text as a piece of factual writing that discusses pollution, its causes and consequences, and ways to address it. That is, these words are both 'textually and topically loaded'.

Through this topic-related vocabulary, we can see an account of textual interaction in action here: the content words or micro-devices interact with the larger macro-organization to activate and shape the rhetorical problem-solution pattern of the text. Essentially, these content words are part of a larger pool of lexical-grammatical resources that the writer has selectively drawn upon to convey to the reader his or her intended message or meanings (cf. Micken, 2003; see also Hoey's (2005) notion of lexical priming, which suggests that repeated use of given words in specific contexts primes users to employ those words and other associated words most frequently in those contexts, or Hunston's (2008) notion of 'what is often said' in a given discourse).

Our small survey and discussion thus far suggest three points central to the implications of texts as critical learning resources: first, texts both shape and are shaped by discourse patterns and the linguistic realizations that accompany them; second, texts, discourse patterns and lexical-grammatical selections are choices that are deeply rooted in the socio-cultural practices of language users to perform particular functions; and third, discourse patterns and lexical-grammatical selections interact with each other, as guided by the interaction between writer and reader (or speaker and listener in spoken discourse), to realize the intended functions or goals. Together these points emphasize that effective communication, both spoken and written, entails being able to appreciate and draw upon relevant language resources in specific ways that reflect clearly and closely how texts function and are employed in particular contexts.

\section{Texts as language learning resources}

The message here for teachers is that if a major goal of instruction is to enable students to successfully comprehend or interpret (i.e., listen and read) and effectively produce (i.e., speak and write) particular texts, we will have to guide them to gain a deep appreciation and control of the different functions, meanings, structures and lexical-grammars of different kinds of texts. One useful way, from my experience, is to engage student in a recursive three-stage learning process or framework known as EAR: Exploration, Analysis and Reflection. Before discussing these three learning stages in detail, however, a brief note is necessary on the selection of texts that helps to maximize opportunities for language learning.

In the light of our earlier discussion and our extensive experience with language, it should not be difficult to realize that texts are fundamentally topic and genre-based. That is, we can classify texts according to topics, text types, the purposes they serve or the functions they perform. To exploit texts for language learning then, the teacher could begin by assembling as learning material a collection of seven to 15 topic and genre-specific texts, written and spoken (e.g., recordings), of a length appropriate to learners' proficiency level (generally between 150 and 800 words for school students). Let us call this collection of texts a 'pedagogic corpus' (Willis, 1993). For secondary school students, for example, 


\section{MORE THAN WORDS: TEXT MATTERS IN LANGUAGE LEARNING}

we may have a pedagogic corpus of pollution texts which consists of 12 carefully selected factual texts, or a corpus of 13 narrative texts illustrating stories on moral values (e.g., for those teachers whose teaching contexts are guided by the Malaysian curriculum specifications). We may also collect about 10 expository texts on Financial Management for college students of Business Studies. What is important to note here is that the topic and genre selected should be of relevance to the students' academic or professional lives.

It should also be noted that my suggestion of assembling seven to 15 texts on the same topic and genre depends largely on learners' (un)familiarity with the topic under discussion. When the teacher is teaching a group of learners who have little knowledge on a selected topic, for instance, encouraging learners to read and process seven to 15 texts of the same topic will help to develop and enrich the learners' background knowledge about the topic. If, however, the teacher is having an upperintermediate group of learners who read and travel widely, then I would suggest that two to five texts may suffice. One may wonder at this point how to go about sustaining the so-called beginning or lower intermediate learner's interest in processing a pedagogic corpus of seven to 15 texts. This is an issue we consider in the next section, which discusses the three-stage learning framework as noted earlier.

\section{The Exploration stage}

As the first stage within a recursive EAR framework, the Exploration stage is essentially a textexploration and schema-building stage. The main focus here is on meaning and on engaging students in meaningful interaction with texts (spoken and written). Students perform a series of classroom tasks, activities and exercises that are devised from topic- and genre-specific texts, in order of perceived challenge or difficulty. These tasks could range from main-point identification and information transfer (e.g., semantic mapping, text-based charts completion, text-based picture drawing) to information gap tasks, group discussions and oral presentations. The primary concern for employing a series of tasks, activities and exercises here is to ensure that students approach the texts to gain familiarity with the relevant linguistic, structural and content knowledge in general in order for them to be deeply engaged with the particular topic under exploration.

Given our focus at the moment on sustaining the learner's interest in exploring seven to 15 texts on the same topic and genre, the importance of the notion of 'variety' becomes apparent. As should be clear from the preceding discussion, we value variety in the form of tasks, activities, exercises and learning experiences. In other words, we arouse and sustain the learner's interest through a variety of methodological strategies that bring together the four skills of listening, speaking, reading and writing in an integrated manner. I have provided some ideas on how to go about encouraging the learner to explore and process seven to 15 texts through a range of (traditional) tasks, activities, exercises and learning experiences in Chau (2004a); more suggestions on creative methodology can be found in Harmer (2007) and other titles especially in Longman's 'How-To' series (see also Flowerdew, 2012, for a discussion of using corpora in the classroom; or Anderson, 2014, on ways of developing students into engaged readers).

\section{The Analysis stage}

It is important to point out that mere exploration of topic and genre-specific texts, though crucial, does not guarantee students' awareness of the interactive nature of texts, especially in the case of low proficiency students. The Analysis stage is, therefore, essential: at this stage, students are guided to analyze the seven to 15 texts processed earlier at the Exploration stage for a common textual pattern that emerges across the texts and for the typical lexical-grammatical realizations that accompany them. This is a stage that promotes noticing and pattern extraction with the aim to ensure that students develop 


\section{MORE THAN WORDS: TEXT MATTERS IN LANGUAGE LEARNING}

an explicit understanding of what constitutes a social-culturally valued text, how target texts are organized and why they are produced in the ways they are with the accompanying linguistic resources.

In my own classroom, I usually begin this stage with a text reconstruction task (see below) using one of the texts processed at the preceding stage. (Notes: The following jumbled paragraphs are taken from the Pollution text noted earlier. For space and copyright reasons, only the first sentence of each paragraph is shown.)

First of all, existing laws and regulations aimed at reducing pollution should be strictly enforced.....

Reducing pollution requires efforts by all parties concerned - the government, industries and consumers. ....

Another important step to curb pollution is to educate the public on the effects of pollution and how they can help protect the environment. ....

Pollution was once thought to be the inevitable price for modernization and industrialization. ....

Lastly, more people should be made aware of buying environmentally safe products and these should be reasonably priced to be attractive to the average consumer.

This initial task is useful in that it encourages deeper processing of discourse structure among the students and more importantly, gives them a sense of achievement. Personal experience suggests that having performed all the text-based tasks at the Exploration stage, most students can complete the task with ease.

Subsequent tasks will capitalize on the student motivation gained here after a discussion session on how students arrive at their chosen sequence of paragraph arrangement. These include identifying the discourse pattern and the linguistic co-occurrences of the same text. Examples of useful guiding questions for a group of upper secondary students aged 17, for instance, after the whole class has identified the rhetorical pattern (in our case, the problem-solution pattern), include:

- Are there any words that explicitly signal to you the problem-solution pattern?

What are they?

- What are the words/phrases used to describe the problem? What about solutions?

- The word 'should' occurs six times in the text, as follows:

1....existing laws and regulations aimed at reducing pollution should be strictly enforced.

2. ...industries should be equipped with proper waste-treatment systems. 


\title{
MORE THAN WORDS: TEXT MATTERS IN LANGUAGE LEARNING
}

\author{
3. The Department of the Environment and the Road Transport Department, \\ respectively, \\ regulations. \\ should ensure that industries and vehicle owners comply with environmental \\ 4. ...more people should be made aware of buying environmentally safe products and these \\ $\underline{\text { should }}$ \\ be reasonably priced to be attractive to the average consumer. \\ 5 ....there should be more encouragement for consumers to buy environment-friendly products.
}

Why do you think they are so frequently used in this particular text?

- What is/are the tense/tenses used here? Why do you think this/these particular tense/tenses are used?

- From the words/phrases used to describe both the problem and the solutions as well as from the frequent use of 'should', what do you think the writer's stand is on this issue? Are there any other words or evidence that further supports your view?

At this stage too, students are required to start assembling a list of content words specific to the topic of the text under analysis. This list may contain groups of topic-related words that characterize the text, like the one shown earlier for the Pollution text where there are words and/or phrases grouped under the headings of Words connected with the problem, Words connected with the causes or consequences of the problem and Words connected with the solutions to the problem. Students can also be required to further classify the words identified into the categories of nouns, verbs, adjectives and adverbs. This could serve a useful way to make form and function relationships transparent and highlight the use of linguistic devices for making meanings.

The next step after this single-text analysis phase is to observe whether or not the same discourse structure emerges across the other topic and genre-specific texts already studied. Obviously, students will find the same recurring structure. At the same time, they will notice a great number of frequently recurring words and phrases across the texts that characterize the topic. The phrase environmental pollution, for example, occurs 12 times in a pedagogic corpus that I have assembled of 13 Pollution texts, and the phrase reduce/reducing (environmental) pollution occurs 10 times.

In addition, students will find a wealth of other language learning opportunities in the texts: in the Pollution pedagogic corpus mentioned earlier, I find repeated use of reduce, reducing and reduction which promotes the learning of different members of the same word family; I also find a number of functionally or semantically related sets of words that collocate with pollution such as \{curb, eliminate, prevent, reduce, keep ... to a minimum $\}$ and \{cause, contribute to, responsible for, result in, worsen the rate of\}, which help to enhance the development of phraseological competence on the topic of pollution among students. Frequent meetings of recurrent linguistic features of this kind contribute to effective vocabulary learning (see, e.g., Chau, 2004b; Webb, 2007), and some ideas on how to direct and guide students to notice recurring lexical items and patterns in topic- and genre-specific pedagogic corpora can be found in Chau (2003).

A final step at this Analysis stage requires students to compile a list of all topic-related words and phrases found across the texts, and to categorize them, again, into groups - a process similar to what they have done for the text in the single-text analysis phase. Getting students to work with a personal computer here is a useful way to help them to complete the vocabulary compilation task more efficiently. This task as a whole may seem to be time-consuming, but students can always work in pairs or in groups to complete it. Crucially the process gives a very good return for learning efforts. By the 


\section{MORE THAN WORDS: TEXT MATTERS IN LANGUAGE LEARNING}

end of the unit, they will have built a large vocabulary specific to the topic and genre in focus. Further 'practice' tasks, such as giving an oral presentation or completing relevant writing tasks, may of course be introduced, giving students the opportunity to apply and consolidate what they have learnt.

\section{The Reflection stage}

This is a stage at which students are encouraged to reflect on the texts they have studied, the linguistic co-occurrences they have come across, the possibility of other alternatives, the wider socio-cultural, textual as well as personal factors that motivate text production and linguistic selections, and the strategies they can draw upon and have used in both interpreting and producing texts. There are a number of excellent suggestions offered in the literature (e.g., Johns, 1997; cf. Murphy, 2014) concerning how to go about encouraging reflection among students, and here are some of them in the form of reflection questions that can be posed to students at a more advanced level:

- What are the features of the texts that make them typical or look alike?

- Why do you think the texts are organized in the same way?

- What do you notice about the words, phrases and tenses in these texts?

- Did you come across repeated words and phrases across the texts? Why do you think they are so frequent?

- How does reading this set of texts differ from reading other texts that you have come across? Why?

- What specific strategies have you used when reading the texts? Did you pause to take notes and mark the texts? Where? Why? Did you look up some words in a dictionary, or simply guess the meanings of the unknown words? What are these words, and why?

- Do you agree with all the views expressed by the writers of these texts? Which do you agree with, and which you don't? Why?

- How do you think the writers of these texts planned as they wrote these texts?

- What resources can you make use of from these texts to assist your speaking and/or writing tasks?

At college or university level, further questions can be used to encourage student reflection once the students have completed an oral or a written assignment based on the same topic:

- What was your main problem in completing this assignment and how did you solve it?

- How did you arrive at the organization of your oral presentation/writing? Which specific words or phrases did you use and like? Why did you make this choice? What does this choice tell us about you as a competent speaker or writer?

- Which specific part, do you think, your audience/reader is likely to find effective and persuasive of your presentation/writing?

- What other resources (e.g., a collocations dictionary or any other texts outside the class) have you made use of to assist your speaking/writing task? How useful did you find them?

- Are you satisfied with your task performance? Why or why not?

The main focus of these reflection questions is to encourage students to reflect on their learning processes and prompt them to think of strategies they might want to consider in advancing their use and learning of the target language.

When students have completed a topic and genre-based unit of learning, the whole process, based on the EAR stages, repeats with another topic- and genre-specific pedagogic corpus being introduced and 


\section{MORE THAN WORDS: TEXT MATTERS IN LANGUAGE LEARNING}

processed. This further encourages students to make sense of how texts are realized for specific purposes in particular contexts and what specific language resources might be preferred over others in different contexts.

As a final note to this section, the EAR framework should be seen as a flexible supporting framework for learning. The whole EAR process, as I have suggested elsewhere (Chau, 2004c), is a recursive one (see Figure 2). Like a genre-based curriculum cycle (Cullip, 2004), teaching based on the EAR framework may move between stages of exploration, analysis and reflection, backtracking and skipping when and if appropriate, depending on the context and students one has.

\section{Exploration}

(a main focus on meaning)

Analysis

(an explicit focus on form)

\section{Reflection}

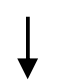

$$
\begin{aligned}
& \mathbf{4} \\
& \mathbf{1} \\
& \mathbf{1} \\
& \mathbf{1} \\
& \mathbf{1} \\
& \mathbf{1} \\
& \mathbf{1}
\end{aligned}
$$

Figure 2:An EAR framework

\section{Text and the learner}

A recurring argument of this paper is the need to selectively employ texts and devise tasks based on these texts to (1) cultivate in language learners a deep appreciation of the interactive nature of texts, and to (2) enable them to gain control of differentiating the functions, meanings, structures and lexicalgrammars of different kinds of texts and pressing them into communicative service. I have suggested that this can be done through exploiting collections of seven to 15 topic and genre-specific texts in relation to tasks framed within a recursive EAR framework.

It is not difficult to see the advantages of tapping texts as language learning resources based on a recurrent topic and genre, and deriving tasks from them to allow learners to approach the texts. They are as follows:

- the ongoing texts with tasks built upon them provide support for learning to take place in order of linguistic and cognitive difficulty;

- the recurring textual pattern and linguistic features in the texts encourage recycling of contextualized language use;

- $\quad$ each ongoing text provides a model for further reproduction that eventually provides a basis for more creative language use in context; and

- texts exploited within an EAR framework contribute to developing learners' conscious awareness of the processes underlying text interpretation and creation in specific contexts, and provide for learners self-reflection opportunities to lead to a greater sensitivity towards their own learning processes in encountering the target texts and in producing their own texts. 


\section{MORE THAN WORDS: TEXT MATTERS IN LANGUAGE LEARNING}

While all these points are consistent with some principles proposed in language teaching and learning such as scaffolding, recycling, reproduction to creation, integration and active learning (e.g., Nunan, 1999; see also Nation, 2007; Ellis, 2014), I acknowledge that students may have their own personal agendas for learning. I am also aware that they have their own learning styles and preferences. Judging from a number of years of very encouraging feedback from students after they had gone through several units of topic and genre-based learning, however, I am convinced that texts which are carefully selected and connected with well-developed tasks satisfy learners' demands for personal relevance and provide for them valuable language learning resources and experience.

Some illustrative comments from a number of students who have completed learning units based on topic- and genre-specific texts are provided below:

'I really like this way of learning. We can learn to speak properly and the grammar is very useful. B'cos we not learn like this before. We also know more words and meaning.'

'I think it is a good way to improve my essay writing as well as my vocabulary. ... I can remember some new words and even beautiful phrases and use it in my essay. I also discovered that my listening and speaking skills have improved a lot.'

'I find that through about 10 texts on the same topic, my grammar has improved. I know more vocabulary than before. Read about 10 texts on the same topic, it can remind me about the same words, phrases that useful to me. When writing an essay like this, I have many ideas which I have learned before. ... my pronunciation good than before. I think we should always do like that. About those 'signalling words', they are also useful to me, but very hard to find those words.'

'After reading about 10 text on the same topic, I think I manage to learn more vocabulary which has the same meaning. It helps me in essay writing and summary writing. Apart from this, I think I can understand the topic better and the effective way - writing down the similar words in the same group - help us in writing. Lastly, I would like say thank you!!!'

While all these comments may sound overwhelmingly positive, I must also point out that introducing the line of discourse approach which I have proposed in this paper is not without its concerns or problems. A serious teacher, for example, may be quick to spot some glaring 'errors' made by the students as shown in the written comments above. But instead of seeing the errors as an indication of limitations or deficiencies of the approach, I would suggest that those signs indicate that the students were making good progress in the language: they have become much more 'adventurous', if not more confident, in using the language (than before). They have, in fact, been able to produce longer stretches of meaningful language. They are, in other words, steadily developing their control of the language at the discourse level.

Perhaps a real concern here is for teachers (rather than students) to 'change' or to introduce a seemingly 'new' approach in the classroom; old habits die hard, as we often hear. Indeed initiating a change in classroom practice often requires time, and it takes great courage for one to make this change. But I believe that there is nothing really radically new in the approach outlined here. Some effort and time may be required initially to assemble collections of topic- and genre-specific texts, but these materials can always be re-used later or 'updated' and replaced with new, relevant texts when one is having new 


\section{MORE THAN WORDS: TEXT MATTERS IN LANGUAGE LEARNING}

groups of students. I also tend to think that the approach I have discussed is flexible enough to be introduced and incorporated into most, if not all, curricula.

One way forward is perhaps to start experimenting and applying insights a little at a time. Try 'applying the insight to a part of your course and see how it affects other parts of the course', advises Woodward (1996, p. 9) when she talks about wrestling with change. 'You may start with an apparently tiny change and find that the ripple effect is considerable and beneficial throughout the rest of the course'.

\section{Conclusion}

In this paper, I have pursued the line of discourse analysis and enquiry popularized by the late Eugene Winter and Michael Hoey, with further insights from Michael McCarthy's approach to pedagogical discourse analysis and Michael Halliday's notion of language as social semiotics I have drawn upon a pedagogic text as an example of texts regularly encountered by Malaysian learners in general in instructional settings, examined its underlying discourse pattern and looked at how topic-related vocabulary as part of a larger pool of linguistic resources at the micro level interacts with macro features to activate and shape the rhetorical pattern of the text. I have also offered some suggestions on how to go about maximizing language learning opportunities through exploiting topic- and genre-specific texts framed within an EAR framework, and reported some learners' comments and feedback on the approach I had adopted in my classroom. Perhaps it should also be noted that although I am writing with a Malaysian readership in mind, the discussion presented in this paper is relevant more widely.

I hope the approach suggested here is not seen as the single best approach, but one of several best practices. The discussion in this paper complements most other discussion on discourse analysis which focuses on spoken interaction as reflected in such approaches as exchange structure and conversation analysis (e.g., McCarthy \& Walsh, 2003; see also Cook, 2011). Texts that are exploited according to topic and genre, I have argued, meaningfully engage learners and provide them with an explicit understanding of what constitutes a social-culturally valued text, how target texts are organized and why they are produced in the ways they are (cf. Hyland, 2008).

A further issue that requires attention, but which might be discussed elsewhere for reasons of space here, concerns the role of text in the education of young persons. That is, if language education is to fulfil purposes of education in general and if the interpretation and production of texts are to be considered as a major part of our daily social-cultural practices, how should we approach the use of texts? How do we transmit values to students through texts? And how do we go about making students' encounter with texts an ongoing educational experience? These are questions for further exploration, ones which may point the way to more effective educational practice (e.g., Chau \& Kerry, 2008; see also Achugar \& Schleppegrell, 2016; Williams, 2016). But for now, I hope I have done enough to suggest that text matters in language learning, and likely beyond.

\section{References}

Achugar, M., \& Schleppegrell, M. (2016). Reflection literacy and the teaching of history. In L. W. Bowcher, \& Y. J. Liang (Eds.), Society in language, language in society: Essays in honour of Ruqaiya Hasan (pp. 357-378). Basingstoke: Palgrave. 


\section{MORE THAN WORDS: TEXT MATTERS IN LANGUAGE LEARNING}

Anderson, N. J. (2014). Developing engaged second language readers. In M. Celce-Murcia, D. Brinton, \& M. Snow (Eds.), Teaching English as a second or foreign language, 4th ed (pp. 170-188). Bonton, MA: Heinle \& Heinle.

Celce-Murcia, M., \& Olshtain, E. (2000). Discourse and context in language teaching: A guide for language teachers. Cambridge: Cambridge University Press.

Celce-Murcia, M., \& Olshtain, E. (2014). Teaching language through discourse. In M. Celce-Murcia, D. Brinton, \& M. Snow (Eds.), Teaching English as a second or foreign language, 4th ed (pp. 424-437). Bonton, MA: Heinle \& Heinle.

Chau, M. H. (2003). Contextualizing language learning: The role of a topic- and genre-specific pedagogic corpus. TESL Reporter, 36 (2), 42-54.

Chau, M. H. (2004a). Integrating and developing language skills: The role of a topic- and genre-specific pedagogic corpus. In S. A. Abdullah (Ed.), Preparing students for the Malaysian University English Test (MUET) (pp. 35-59). Petaling Jaya: Sasbadi.

Chau, M. H. (2004b). Making the reading classroom acquisition-rich: An elaborated schema perspective. In B. Wijasuriya \& F. Hashim (Eds.), Reading connections (pp. 11-28). Petaling Jaya: Sasbadi.

Chau, M. H. (2004c). Developing and exploiting topic- and genre-specific pedagogic corpora. In S. Rafik-Galea (Ed.), ELT materials: Theory and practice (pp. 169-189). Petaling Jaya: Sasbadi.

Chau, M. H., \& Kerry, T. (2008). International perspectives on education. London: Continuum/Bloomsbury.

Cook, G. (2011). Discourse analysis. In J. Simpson (Ed.), The Routledge handbook of Applied Linguistics (pp. 431-444). London: Routledge

Cullip, P. F. (2004). Writing in context: A genre-based approach. In K. Kaur (Ed.), Second language writing (pp. 199-229). Petaling Jaya: Sasbadi.

Ellis, R. (2014). Principles of instructed language learning. In M. Celce-Murcia, D. Brinton, \& M. Snow (Eds.), Teaching English as a second or foreign language, 4th ed (pp. 31-45). Bonton, MA: Heinle \& Heinle.

Ferris, D. (2011). Written discourse analysis and second language teaching. In E. Hinkel (Ed.), Handbook of research in second language teaching and learning, vol. 2 (pp. 645-62.). New York, NY: Routledge.

Flowerdew, L. (2012). Corpora in the classroom: An applied linguistic perspective. In K. Hyland, M. H. Chau, \& M. Handford (Eds.), Corpus applications in applied linguistics (pp. 208-224). London: Continuum/Bloomsbury.

Gardner, H. (1993). From conflict to clarification: A comment on Egan's "Narrative and Learning: A Voyage of Implications". Linguistics and Education, 5, 181-185.

Halliday, M. A. K. (1978). Language as social semiotic. London: Arnold Press.

Harmer, J. (2007). The practice of English language teaching (4th ed). Essex: Pearson. 


\section{MORE THAN WORDS: TEXT MATTERS IN LANGUAGE LEARNING}

Hoey, M. (1983). On the surface of discourse. London: Allen \& Unwin.

Hoey, M. (2001). Textual interaction: An introduction to written discourse analysis. London: Routledge.

Hoey, M. (2005). Lexical priming: A new theory of words and language. London: Routledge.

Hunston, S. (2008). Starting with the small words: Patterns, lexis and semantic sequences. International Journal of Corpus Linguistics, 13(3), 271-295

Hyland, K. (2008). Genre and academic writing in the disciplines. Language Teaching, 41, 543-562.

Johns, A. M. (1997). Text, role and context: Developing academic literacies. Cambridge: Cambridge University Press.

McCarthy, M. (1991). Discourse analysis for language teachers. Cambridge: Cambridge University Press.

McCarthy, M., \& Walsh, S. (2003). Discourse. In D. Nunan (Ed.), Practical English language teaching (pp. 173-195). New York, NY: McGraw-Hill.

Mickan, P. (2003). Beyond grammar: Text as unit of analysis. In J. E. James (Ed.), Grammar in the language classroom: Changing approaches and practices (pp. 220-227). Singapore: SEAMEO Regional Language Centre.

Murphy, J. M. (2014). Reflective teaching: Principles and practices. In M. Celce-Murcia, D. Brinton, \& M. Snow (Eds.), Teaching English as a second or foreign language, 4th ed (pp. 613-629). Bonton, MA: Heinle \& Heinle.

Nation, I. S. P. (2007). The four strands. Innovation in Language Learning and Teaching, 1, 1-12.

Nunan, D. (1999). Second language teaching and learning. Boston, MA: Heinle \& Heinle.

Paltridge, B. (1996). Genre, text type and the language classroom. ELT Journal, 50, 237-243.

Sinclair, J. (2004). Trust the text: Language, corpus and discourse. London: Routledge.

Thornbury, S. (2005). Beyond the sentence: Introducing discourse analysis. Oxford: Macmillan.

Webb, S. (2007). The effects of repetition on vocabulary knowledge. Applied Linguistics, 28, 46-65.

Williams, G. (2016). Reflection literacy in the first years of schooling: Questions of theory and practice. In L. W. Bowcher, \& Y. J. Liang (Eds.), Society in language, language in society: Essays in honour of Ruqaiya Hasan (pp. 333-356). Basingstoke: Palgrave.

Willis, D. (1993). Syllabus, corpus and data-driven learning. IATEFL Conference Report: Plenaries.

Winter, E. O. (1986). Clause relations as information structure: Two basic text structures in English. In R. M. Coulthard (Ed.), Talking about text. Birmingham: English Language Research. 
Woods, N. (2007). Learning and teaching discourse analysis. Subject Centre for Languages, Linguistics and Area Studies Good Practice Guide. Retrieved 7 December 2008, from http://www.llas.ac.uk/resources/gpg/2824.

Woodward, T. (1996). Paradigm shift and the language teaching profession. In J. Willis \& D. Willis (Eds.), Challenge and change in language teaching (pp. 4-9). Oxford: Heinemann.

\section{Contact Details of Author}

Chau Meng Huat

Department Of English Language

Faculty of Languages \& Linguistics

University of Malaya

50603 Kuala Lumpur

MALAYSIA

chaumenghuat@um.edu.my

\section{Biodata}

Meng Huat CHAU (PhD, Birmingham) is Senior Lecturer at the University of Malaya, where he coordinates the M.A. (Linguistics), and teaches and supervises at postgraduate level in Applied Linguistics. His research focuses on corpus linguistics and educational linguistics, in particular the study of language development and (critical) multilingualism. 